\title{
(IM)POSSIBILIDADE DE APLICAÇ̃̃O DAS REGRAS DE RECUPERAÇÃO JUDICIAL E DE FALÊNCIA ÀS SOCIEDADES DE ECONOMIA MISTA QUE ATUAM COMO AGENTES ECONÔMICOS
}

\author{
(IM)POSSIBILITY OF APPLICATION OF THE RULES OF JUDICIAL RECOVERY \\ AND BANKRUPTCY TO THE COMPANY OF MIXED ECONOMY THAT ACT AS \\ ECONOMIC AGENTS
}

\author{
André Lipp Pinto Bastos Lupi ${ }^{1}$ \\ Lucas Amaral Dassan ${ }^{2}$ \\ João Paulo do Carmo Barbosa Lima3
}

\section{Resumo}

A questão abordada na pesquisa está ligada à possibilidade de aplicação das regras da falência e da recuperação judicial às sociedades de economia mista que atuam como agentes econômicos. A sociedade de economia mista é forma de intervenção do Estado na Economia por meio do exercício da administração pública indireta. Calcada em seu conceito mais básico, as sociedades de economia mista apresentam um amalgama de capital provindo do Estado e derivado de Particulares, atuando tanto na esfera da prestação de serviços públicos, quanto na economia enquanto presentes os critérios constitucionais que autorizam uma intervenção. Ademais, o regime jurídico que seguem está vinculado ao direito privado. Neste viés, bem como sob os pressupostos de que não poderiam ser destinatárias de privilégios diferenciados em relação às empresas da esfera privada, questiona-se: seria possível a aplicação das regras da recuperação judicial e da falência a estas entidades? Quais seriam os pontos de divergência? O presente trabalho tem por objetivo geral a proposição da análise da sociedade de economia mista como fonte de intervenção do Estado na Economia, especialmente quanto a atuação da mesma como agente econômico e suas consequências nos casos em que podem passar por dificuldades econômicas e necessidade de decretação de sua falência ou de sua recuperação judicial. Por este viés, procura-se estabelecer o seu grau de igualdade perante os demais agentes econômicos da esfera privada e em face do seu regime privado. De forma subsequente, buscará

\footnotetext{
1 Possui graduação em Direito pela Universidade Federal de Santa Catarina (1997), mestrado em Direito pela Universidade Federal de Santa Catarina (2000) e doutorado em Direito pela Universidade de São Paulo (2006), com estágio doutoral no Institut de Hautes Études Internationales de Genebra. Realizou Estágio Pós-Doutoral na Universidade de Lisboa (2016-2017). Atualmente é professor do Programa de Mestrado em Direito Empresarial do Unicuritiba. Professor associado do Centro Universitário de Brasília (UniCeub). Foi Professor de Direito Empresarial da Universidade Federal de Santa Catarina, professor da Universidade do Vale do Itajaí, nos programas de Mestrado e Doutorado em Ciência Jurídica e de graduação em Direito e Relações Internacionais. Professor convidado do Doutorado em Ciência Jurídia da Pontificia Universidade Javeriana de Bogotá.

2 Mestrando em Direito Empresarial e Cidadania no Centro Universitário Curitiba - UNICURITIBA. Curitiba - PR. Possui graduação em Direito pelo Centro Universitário Curitiba (2006). Detém Especialização pela PUC/PR em Processo Civil Contemporâneo (2008) e, na mesma universidade, Especialização em Direito Civil e Empresarial (2014). E-mail: lucasdassan@hotmail.com

${ }^{3}$ Mestrando em Direito Empresarial e Cidadania no Centro Universitário Curitiba - UNICURITIBA. Curitiba - PR. Possui graduação em Direito pela Pontifícia Universidade Católica do Paraná (2003). Detém Especialização pela PUC/PR em Direito Civil e Empresarial (2004) e Direito Tributário e Processo Tributário (2013). E-mail: jpbarbosalima@hotmail.com
} 
ser esclarecida a possibilidade ou não da aplicação das regras de recuperação judicial e ou de falência, específicas ou não, a estes agentes.

Palavras-chave: Sociedade de Economia Mista; Intervenção no domínio econômico; Regime Jurídico Privado; Recuperação Judicial e Falência.

\begin{abstract}
The question addressed in the research is linked to the possibility of applying the rules of bankruptcy and judicial recovery to Company of Mixed Economy that act as economic agents. The Company of Mixed Economy is a form of state intervention in the economy through the exercise of indirect public administration. Based on its most basic concept, Company of Mixed Economy present an amalgam of state and private capital, acting both in the sphere of public service provision and in the economy, while bearing in mind the constitutional criteria that authorize a corresponding intervention. In addition, the legal regime that follows is linked to private law. In this regard, as well as under the assumptions that they could not be recipients of differentiated privileges in relation to companies in the private sphere, it is questioned: Is it possible to apply the rules of judicial recovery and bankruptcy to these companies? What are the points of divergence? The purpose of the present work is to propose the analysis of the Company of Mixed Economy as a source of State intervention in the economy, especially as the economic agent and its consequences in the cases in which they may suffer economic difficulties and the need to decree his bankruptcy. By this bias, it seeks to establish its degree of equality before the other economic agents of the private sphere and in face of its private regime. Subsequently, it will seek to clarify the possibility or otherwise of applying the rules of judicial recovery and / or bankruptcy, specific or otherwise, to these agents.
\end{abstract}

Key-words: Company of Mixed Economy; Intervention in the economic domain; Private Legal Regime; Judicial Recovery and Bankruptcy.

\title{
1 INTRODUÇÃO
}

No contexto brasileiro é possível observar diversas formas de atuação do Estado no ambiente econômico, decorrentes de imposição constitucional (CF/88, art. 170), inclusive através de entidades estatais que fazem parte da administração pública indireta.

Nesta conjuntura, reverberam diversas regras e princípios constitucionais e infraconstitucionais que sistematicamente disciplinam o regime jurídico de cada uma dessas entidades.

A situação se torna mais nebulosa quando determinado feixe de normas jurídicas enseja uma espécie de interpretação, enquanto outras, conforme interpretação aplicável, acabam trazendo não só uma antinomia normativa, mas também dão ensejo a situações de cunho fático relevante e problemático do ponto de vista econômico; muitas vezes, levando à possibilidade de indicação de que determinadas normas seriam, na realidade, inconstitucionais. 
As circunstâncias então salientadas, no caso da intervenção do Estado na Economia, tornam-se bastante enfatizadas, já que em face de determinadas entidades estatais é aplicado o regime jurídico público enquanto, em face de outras, resta aplicável o regime jurídico privado.

Com maior especificidade, tornam-se também nuviosas a aplicação ou não de determinadas normas, especialmente infraconstitucionais, às entidades estatais que exercem atividade econômica, ganhando maior relevo aquelas em que há uma combinação de capital público e privado, como no caso das Sociedades de Economia Mista.

Entre as várias possibilidades fáticas enfrentadas por referidas entidades, estão aquelas atinentes às regras de mercado e, principalmente, quanto ao possível enfrentamento de dificuldades econômicas.

Diante deste contexto, observando-se o ordenamento jurídico pátrio atual, existe a problemática sobre a vigência das normativas envolvendo a sistemática geral de recuperação judicial e de falência, quando incidentes casos de dificuldades econômicas enfrentadas pelas entidades estatais, especificamente aquelas que se utilizam de capital heterogêneo.

Dessa forma, a pesquisa apresentada tem por objetivo geral a proposição da análise da Sociedade de Economia Mista como fonte de intervenção do Estado na Economia, especialmente quanto a atuação da mesma como agente econômico e suas consequências nos casos em que podem passar por dificuldades econômicas e necessidade de decretação de sua falência ou de sua recuperação judicial.

Em proposição mais específica, o objetivo do artigo está vinculado a duas questões: é possível a aplicação das regras da recuperação judicial e da falência às Sociedades de Economia Mista? Quais seriam os pontos de divergência?

Justifica-se o aprofundamento quanto ao tema justamente para esclarecer as questões jurídicas sobre a incidência das referidas normativas, ensejando melhor compreensão sobre as consequências econômicas advindas da sua aplicação às referidas entidades, com efeitos pragmáticos no campo fático e econômico que poderiam gerar maior praticidade à forma de enfrentamento das dificuldades econômicas, sem ensejar comprometimento com o estatuto constitucional e com os princípios gerais aplicáveis, especialmente quanto à impossibilidade de concessão de privilégios desleais ou mesmo deturpações de destinação quanto ao capital e aos bens envolvidos.

De outra forma, o estudo também possui serventia para equalizar a possibilidade de indicação da inconstitucionalidade de determinadas normas atinentes à sistemática de falência e recuperação judicial. 
Por este aspecto, utiliza-se do método dedutivo, analítico e descritivo para construção do trabalho em análise. Dedutivo, pois é observado um fenômeno geral atinente à intervenção do Estado na Economia, as regras gerais aplicáveis, partindo-se para situações com maiores especificidades envolvendo o regime jurídico das Sociedades de Economia Mista, em especial aquelas que interveem diretamente na economia, contrapondo-se às dificuldades econômicas com possibilidade ou não da aplicação de determinadas normas específicas sobre falência e recuperação judicial, correlacionando-as pela lógica legal; analítica, pois percorre o estudo e avaliação aprofundada da natureza jurídica das entidades indicadas, do regime jurídico aplicável e dos institutos gerais e específicos; descritiva, pois salienta a opinião de diversos doutrinadores sobre o assunto em pauta, contribuindo para a análise dos pontos de divergência.

Assim, o trabalho desenvolvido demonstra cabal conexão com os assuntos atinentes à Ciência Jurídica, em especial ao ramo do Direito Empresarial, possuindo o condão de abarcar contextualizações e problemáticas concernentes à intervenção da administração pública na economia por meio de entidades que podem ou não se submeterem a determinas normas jurídicas.

\section{DA SOCIEDADE DE ECONOMIA MISTA E DO REGIME JURÍDICO APLICADO:}

As Sociedades de Economia Mista se apresentam como uma espécie de entidade que espelham a atuação do Estado na Economia, sendo uma das formas de exercício da denominada administração pública indireta.

Necessário observar, desde o primeiro momento, que inúmeras são as formas de atuação do Estado na Economia, necessárias para atendimento dos princípios sociais estabelecidos no art. 170 da Constituição Federal.

De forma mais geral, impera a possibilidade de atuação do Estado por meio de funções de fiscalização, incentivo e planejamento (MEIRELLES, 2011, p. 689). Diante desta situação, advém a possibilidade de efetivação, por exemplo, da política fiscal, da política econômica em si e também da geração de regulamentações derivadas das legislações que impactam no mercado econômico.

Segundo José Afonso da Silva (2018, p. 818), as formas de intervenção estatal previstas na Constituição, apesar de não serem claras, definem que o Estado pode ingerir na economia por meio de intervenção ou de participação, instrumentos pelos quais o Poder Público ordena, coordena e atua em observância dos princípios da ordem econômica. 
Celso Antônio Bandeira de Mello salienta, panoramicamente, que a interferência do Estado na ordem econômica objetivando priovilegiar o bem estar social da coletividade, pode ocorrer de três formas: a) por meio do exercício do poder de polícia, desdobrada na atuação de fiscalização e planejamento; b) através de atuação própria, empresarial e de forma excepcional e c) mediante incentivos à iniciativa privada (MELLO, 2015, p. 818).

De maneira mais específica, também é possível observar que a referida atuação poderia se dar pelos seguintes meios: a) monopólio; b) repressão ao abuso do poder econômico; c) controle de abastecimento; d) tabelamento de preços; e) criação de empresas estatais (MEIRELLES, 2011, p. 690).

Quanto à criação de empresas estatais, é possível verificar a possibilidade de atuação do Estado por meio de agentes que explorem diretamente a atividade econômica, através do exercício da administração pública indireta.

Por esses aspectos, deve estar bem claro que para a exploração direta da atividade econômica pelo Estado, há necessidade dessas sociedades seguirem o regramento máximo da Constituição Federal de 1988, exposto em seu artigo 173, o qual salienta que só será permitida referida exploração direta da economia quando necessária aos imperativos da segurança nacional ou o relevante interesse coletivo (BRASIL, 1988).

Dentre as principais categorias de entidades da administração indireta, cujo delineamento se faz importante neste tópico, conforme previsão Constitucional e infraconstitucional, estão: a) as Autarquias; b) as Empresas Públicas; c) as Sociedades de Economia Mista; e d) as Fundações Públicas (MEIRELLES, 2011, p. 798).

Para o estudo em análise, um dos aspectos essenciais é justamente a análise da intervenção do Estado na economia por meio da Sociedade de Economia Mista, que é entidade configurada como pessoa jurídica de direito privado, consubstanciada por meio de capital misto, tanto advindo do Estado (o qual deve ser majoritário), quanto de particulares.

A forma societária adotada deve ser a de Sociedade Anônima, de capital fechado ou de capital aberto, dotada de personalidade jurídica de direito privado e cuja criação depende de autorização legislativa. A atuação dessas entidades pode se dar através da exploração da atividade econômica ou por meio da prestação de serviços públicos.

Vale salientar de forma mais particularizada que o regramento das referidas sociedades está alicerçado tanto no âmbito constitucional, por meio do artigo 37, inciso XIX da CF/88, como através de leis especiais, exemplificado no Decreto-Lei 200/1967, na Lei 13.303/2016 e na Lei 6.404/1976. 
A Sociedade de Economia Mista é, portanto, um instrumento regulador de mercado, pelo qual o Estado atua em conjunto com a iniciativa privada, sob as regras de direito privado e de regulação geral das sociedades anônimas, almejando lucro e satisfação dos "interesses públicos"4.

Referidas considerações são de importância nodal para o estudo realizado, pois conferem a definição certeira das acepções e características das Sociedades de Economia Mista, culminando na demonstração de que a este tipo de entidade é aplicado o regime jurídico privado.

Em primeiro plano, faz-se necessário ressaltar que a própria redação dos parágrafos do artigo 173 da $\mathrm{CF} / 88$ indica a delineação do norteamento geral daquilo que deve ser regulamentado quanto às entidades respectivas. Conforme afirma MEIRELLES (2011):

\begin{abstract}
(...) a lei estabelecerá o estatuto jurídico dessas entidades, dispondo sobre a função social e formas de fiscalização delas pelo Estado e pela sociedade; a sujeição ao regime jurídico próprio das empresas privadas, inclusive quanto aos direitos e obrigações civis, comerciais, trabalhistas e tributários; licitação e contratação de obras , serviços, compras e alienações, observados os princípios da administração pública; constituição e funcionamento dos conselhos de administração e fiscal, com participação de acionistas minoritários; os mandatos, a avaliação de desempenho e a responsabilização dos administradores. (MEIRELLES, 2011, p. 799)
\end{abstract}

Em face dessas indicações programáticas, a Lei $\mathrm{n}^{\circ} 13.303$ de 2016 dispôs sobre o estatuto jurídico da empresa pública, da sociedade de economia mista e de suas subsidiárias, no âmbito da União, dos Estados, do Distrito Federal e dos Municípios; indicando-se raras exceções quanto à sua aplicação.

Referida legislação teve o condão de regulamentar as correlatas normativas constitucionais, bem como complementar o próprio Decreto-Lei no 200 de 1967, o qual já delineava o regramento das entidades estudadas, combinando com as disposições expostas na Lei 6.385/1976 (Lei que disciplina o Mercado de Valores Mobiliários) e na Lei 6.404/1976 (Lei das Sociedades Anônimas), evidenciando a aplicação do regime jurídico de direto privado às Sociedades de Economia Mista.

Dessa conjuntura, podem ser destacadas as características intrínsecas do modelo correlato, de regime jurídico privado: nesta seara são aplicadas as normativas envolvendo princípios e regras concernentes à esfera dos particulares, regulando-se as suas relações

\footnotetext{
${ }^{4}$ Também denominado de "interesse coletivo", conforme se vê do texto do Decreto №. 8.945/16, que regula o Estatuto Jurídico das Estatais.
} 
(PIETRO, 2015, p. 94); todavia, sem deixar de lado a incidência horizontal de direitos fundamentais que poderiam normatizar as referidas relações.

Neste contexto, diferencia-se do regime jurídico de direito público, pois este disciplina organizações e atividades de interesses coletivos, vinculadas direta ou indiretamente à realização dos direitos fundamentais (JUSTEN FILHO, 2005, p. 48).

A regra geral infraconstitucional, no caso das Sociedades de Economia Mista, portanto, é aquela que indica que, salvo disposição em contrário, as pessoas jurídicas de direito público, a que se tenha dado estrutura de direito privado, regem-se, no que couber, quanto ao seu funcionamento, pelas normas do Código Civil, conforme destacado no artigo 40 da Lei 10.406, de Janeiro de 2002).

Importante enaltecer, nesta linha de pensamento, que apesar da aplicação cogente do regime jurídico privado às Sociedades de Economia Mista, alguns doutrinadores, entre eles Celso Antônio Bandeira de Mello, expõem que o referido regime teria um caráter especial no caso de empresas estatais. Isso porque, apesar de estarem restringidas por normativas que lhe conferem limitações em sua atuação, especificamente para não obterem determinados privilégios frente aos particulares, submetem-se a regramentos concernentes à atuação do Estado e da Administração Pública, conferindo-lhes certos aspectos atuantes que as diferenciam, pontualmente, das demais pessoas de direito privado (MELLO, 2009, p. 340).

Dessa forma, observa-se que "ditas criaturas, pois, ainda que modeladas sob o figurino privado, não são, portanto, da mesma cepa que as demais pessoas de direito privado" (MELLO, 2009, p. 340).

Tal se daria em razão da influência que lhe exerceriam determinadas normas de direito público, fomentando diferenças entre referidas entidades, especialmente quanto às Sociedades de Economia Mista em face das pessoas de direito privado puro.

Porém, independentemente deste aspecto delineador, importante frisar que concepções básicas sobre a limitação na forma de atuação de tais entidades face as demais empresas que seguem o mesmo regime deverão imperar justamente em razão da prevenção à concorrência desleal.

Assim, as Sociedades de Economia Mista necessitam estar despojadas de atributos que confeririam desigualdade entre aqueles que atuam na atividade econômica.

Com base nesta premissa é que restou estabelecido o $§ 2^{\circ}$ do artigo 173 da Constituição Federal, determinando que referidas entidades não poderiam gozar de privilégios físcais não extensivos às empresas do setor privado. 
Maior veemência é possível absorver do que apregoa o artigo $173, \S 1^{\circ}$, inciso II da Constituição Federal, o qual impõe norma indicativa de regulamentação por lei infraconstitucional acerca do estatuto jurídico das empresas públicas e sociedades de economia mista que explorem atividade econômica, salientando a sujeição ao regime jurídico próprio das empresas privadas, inclusive quanto aos direitos e obrigações civis, comerciais, trabalhistas e tributários.

O próprio Supremo Tribunal Federal (2008) enfatizou tais características, diferenciando-se as estatais que prestam serviços públicos daquelas que exercem atividade econômica, salientando a seguinte deliberação:

\footnotetext{
Distinção entre empresas estatais prestadoras de serviço público e empresas estatais que desenvolvem atividade econômica em sentido estrito. (...) As sociedades de economia mista e as empresas públicas que explorem atividade econômica em sentido estrito estão sujeitas, nos termos do disposto no $\S 1^{\circ}$ do art. 173 da Constituição do Brasil, ao regime jurídico próprio das empresas privadas. (...) O $\S 1^{\circ}$ do art. 173 da Constituição do Brasil não se aplica às empresas públicas, sociedades de economia mista e entidades (estatais) que prestam serviço público.

ADI 1.642, rel. min. Eros Grau, j. 3-4-2008, P, DJE de 19-9-2008.
}

Com base nos conceitos e características apresentadas, é possível observar que as Sociedades de Economia Mista, fazendo parte do Poder Administrativo descentralizado e da Administração Pública Indireta, são entidade estatal que se submete ao regime jurídico privado, com breves mitigações, aplicando-se normativas correlatas à esfera privada, especialmente para limitar qualquer forma de privilégio ou fomentar concorrência desleal em relação aos particulares que atuam na esfera econômica.

Por este viés, indica-se a incidência do princípio da isonomia e das demais regras e princípios aplicáveis ao regime indicado, desdobrando-se a necessidade de análise quanto a determinados fatos que poderiam ensejar dificuldade quanto à aplicação ou não de determinados institutos às referidas entidades.

Em específico, vislumbram-se as questões atinentes à falência e à recuperação de judicial como pontos nodais de discussão, em especial neste trabalho, sendo questionável a aplicação das regras dos referidos institutos, vinculados ao regime de direito privado em face das correlatas sociedades que exerçam atividade econômica. 


\section{APLICAÇÃO DAS REGRAS DE RECUPERAÇÃO JUDICIAL E DE FALÊNCIA ÀS SOCIEDADES DE ECONOMIA MISTA QUE ATUAM COMO AGENTES ECONÔMICOS:}

Conforme delineado anteriormente, as Sociedades de Economia Mista que atuam como agentes econômicos estariam sujeitas ao regime jurídico privado, mesmo que de certa forma mitigado por determinadas características, por serem entes estatais.

Neste diapasão, evidenciam-se determinados fatos sociais concernentes à atuação destas entidades, que podem fomentar dúvidas de ordem mais complexa.

Como agentes econômicos, as Sociedades de Economia Mista possuem uma natureza jurídica empresarial, submetidas especialmente aos regramentos da Sociedade Anônima, sendo certo que poderão enfrentar os desafios e consequências do mercado econômico. Por este viés, terão para si fatos relacionados às dificuldades relativas ao fluxo financeiro que poderiam desaguar na impossibilidade de continuidade de suas atividades, por pura inviabilidade.

Desse modo, pertinentes são os questionamentos acerca da possibilidade ou da impossibilidade de aplicação das regras concernentes à recuperação judicial ou à falência a estas entidades.

De início, importante salientar que a Lei de Falências (Lei 11.101 de 09.02.2005), em seu artigo $2^{\circ}$, declara não se aplicarem suas disposições às empresas públicas e às Sociedades de Economia Mista, apesar de grande parte da doutrina defender que a referida indicação seria inconstitucional, justamente em razão da equiparação dos referidos entes estatais que exploram atividades econômicas estarem equiparados às empresas privadas (MELLO, 2015, P. 210).

Nesta conjuntura, Bezerra Filho (2009) nos lembra que o artigo 242 da Lei das Sociedades Anônimas (Lei 6.404/76), em primeiro momento, excluía as companhias de economia mista do regime de falência, sendo que o referido dispositivo acabou sendo revogado pela Lei 10.303/2001. Todavia, logo em seguida, com a entrada em vigor da Lei 11.101/2005, houve a indicação expressa da referida regra de exclusão das correlatas entidades estatais da referida sistemática de recuperação e falência. No entender do indicado doutrinador, "a nova Lei de Recuperação deu um passo atrás, pois a tendência era no sentido de valorização da atividade empresarial da sociedade de economia mista" (BEZERRA FILHO, 2009, p. 50).

$\mathrm{Na}$ opinião de Bandeira de Mello (2015), as Sociedades de Economia Mista exploradoras de atividade econômica deveriam seguir normalmente a sistemática de falência e recuperação judicial expostas na Lei 11.101/2005, justamente por estarem inseridas em regime 
jurídico privado, até porque o Estado não poderia responder subsidiariamente pelos créditos de terceiros que ficassem a descoberto, pois estaria sendo outorgada vantagem que não desfrutam as demais empresas privadas (MELLO, 2015, p. 2010).

Vale destacar que tal situação, obviamente, não se daria efetivamente em relação às Sociedades de Economia Mista prestadoras de serviços públicos, já que os bens correlatos seriam classificados como bens públicos, além da necessidade de adequação ao princípio da continuidade dos serviços públicos.

Marlon Tomazette (2014), destaca que a própria doutrina, em princípio, estava dividida quanto aos aspectos atinentes à aplicação dos regramentos indicados às entidades ora em estudo. Todavia, salienta que realmente as empresas estatais prestadoras de serviços públicos estariam excluídas da sistemática respectiva, reconhecendo a vigência do artigo $2^{\circ}$ da Lei 11.101/2005 para essas, mas não aplicável para as que exploram atividade econômica, numa interpretação conforme o artigo 173, §1 ${ }^{\circ}$, II da Constituição Federal (TOMAZETTE, 2014, p. 23-24).

Interessante perceber que no caso das entidades exploradoras de atividades econômicas, analisada sob a perspectiva da sua natureza mista, o capital se faz constituído tanto por patrimônio público, quanto por patrimônio privado, elevando-se o grau de complexidade quanto à referida miscigenação enquanto existente dificuldades econômicas angariadas pelo referido tipo societário.

A saída encontrada inicialmente poderia dizer respeito à simples extinção da sociedade através de autorização legislativa, em conformidade com o Princípio da Simetria por ter sido esta espécie de entidade também criada através de autorização legislativa.

Nesta hipótese, haveria a aplicação da responsabilidade subsidiária do controlador majoritário, no caso uma das pessoas de direito público interno, quanto aos respectivos prejuízos.

Referida situação, ao menos em uma análise sistemática quanto à Sociedade de Economia Mista que explora atividade econômica, entraria em conflito não só com as disposições constitucionais e infraconstitucionais, mas até mesmo com o Princípio da Isonomia, o Princípio da Igualdade e o Princípio da Moralidade Administrativa, pois imporia ao governo a responsabilidade em arcar com os prejuízos deixados por sociedade que também possui capital de particulares.

Neste sentido, Meirelles (2010, p. 401) indica que: 
de economia mista, ficam sujeitas a falência, pois é preceito constitucional sua submissão ao regime jurídico próprio das empresas privadas, inclusive quanto aos direitos e obrigações civis e comerciais (VF, art. $\left.173, \S 1^{\circ}, \mathrm{II}\right)$.

A referida análise retrata, mais uma vez, a necessidade de distinção das Sociedades de Economia Mista que prestam serviços públicos, daquelas que exploram atividade econômica, essencialmente em razão da aplicação do tipo de regime jurídico atrelado aos seus bens respectivos.

Decorre da lógica já analisada em tópico anterior, que aos bens envolvidos na prestação de serviço público estariam afetados e sobre eles incidiriam as regras do regime jurídico de direito público; em contrapartida, aos bens envolvidos em atividades atinentes à economia, seria aplicado o regime jurídico de direito privado.

Sob o prisma da divisão concernente às regras aplicáveis aos bens envolvidos nas atividades correlatas, é possível também referendar o método sistemático de interpretação do ordenamento jurídico para indicar a possibilidade de aplicação metódica de regras gerais da falência e recuperação judicial à determinadas espécies de Sociedade de Economia Mista.

Imperioso trazer os dizeres de Giovani Magalhães (2011), que em trabalho de pesquisa análogo salientou:

De fato, o art. $173, \S 1^{\circ}$, II, da $\mathrm{CF} / 88$ é claro no sentido de dizer que se deve aplicar
às empresas públicas e sociedades de economia mista o mesmo regime jurídico das
empresas privadas, inclusive no tocante às obrigações comerciais. É inegável que a
falência é uma obrigação comercial, inerente e exclusiva, portanto, ao Direito
Comercial. Não se pode olvidar também dos pressupostos para a autorização da
criação de empresas públicas ou de sociedades de economia mista, quais sejam, os
imperativos da segurança nacional ou o interesse coletivo relevante. Relembre-se que
as sociedades de economia mista devem ser constituídas sob a forma de sociedade
anônima e que as empresas públicas podem se constituir por qualquer formato
societário, inclusive, sociedade anônima. (...) sociedade anônima sempre será
empresária, independentemente do seu objeto. Em sendo empresária e tendo
personalidade jurídica de direito privado, devem se submeter ao mesmo regime das
empresas privadas, sujeitando-se ao regime jurídico falimentar, em seu total, ou seja,
podem ter deferida a recuperação judicial ou declarada a falência.

Por referido aspecto, é possível antever que sob o prisma constitucional, as Sociedades de Economia Mista que exercem atividade no domínio econômico estariam realmente sujeitas às regras da falência e da recuperação judicial.

Nesta mesma linha de pensamento, Corrêa-Lima (2009, p. 49) indica:

É incontestável que tanto a empresa pública como a sociedade de economia mista e as outras estatais - desde que todas sejam exercentes de atividade econômica deveriam sujeitar-se à falência, tal como ocorre com o direito obrigacional das empresas privadas, sob pena de, a toda evidência, não estarem sob o mesmo regime 
jurídico próprio das empresas privadas, conforme estabelece [...] disposição constitucional. Assim, parece indubitável que a legislação ordinária realmente vem errando ao impedir a falência da sociedade de economia mista. Esta, sim, se exercente de atividade econômica, pode falir como qualquer empresa privada.

Também é importante considerar as conclusões salientadas por Felipe do Conto Zago (2011, p. 92):

\begin{abstract}
(...) o dispositivo da Lei de Falências não parece mesmo consentir com o artigo 173, $\S 1^{\circ}$, da Constituição Federal, quando as paraestatais exploram atividade eminentemente econômica. Esse último mandamento equiparou sociedades de economia mista e empresas públicas de natureza empresarial às demais empresas privadas, acenando de forma expressa ao direito comercial, dentro do qual, por corolário óbvio, se encontra a Lei de Falências. Incongruente seria admitir a falência para sociedades empresárias e não admiti-la para as sociedades de economia mista e as empresas públicas que exploram a atividade econômica. Seria uma discriminação não avalizada pelo dispositivo constitucional (art. 173), pois ficaram as entidades paraestatais com evidente vantagem em relação às demais sociedades empresárias, apesar de ser idêntico o objeto de sua atividade.
\end{abstract}

Claramente é possível indicar, portanto, que através da diferenciação da estirpe de atividade exercida pela Sociedade de Economia Mista poderá ser aplicada a sistemática de recuperação judicial ou de falência em face da mesma.

\title{
4 CONSIDERAÇÕES FINAIS
}

Das elucidações tracejadas no presente trabalho, é possível delinear determinadas conclusões pormenorizadas, envolvendo o objetivo proposto.

Em primeiro aspecto, observa-se que as Sociedades de Economia Mista se estabelecem como forma excepcional de intervenção do Estado na ordem econômica, sendo parte da estrutura da administração indireta. Em conformidade com o que foi pesquisado, a atuação desses entes públicos pode ser voltada tanto para a prestação de serviços públicos, quanto para, excepcionalmente, a intervenção no domínio econômico.

Em segundo aspecto, é possível considerar que incide sobre as Sociedades de Economia Mista que exercem atividades no domínio econômico as regras inerentes às empresas privadas, ou seja, há aplicação do regime jurídico privado, ainda que pontualmente mitigado pela conexão que possuem com a administração estatal. A referida indicação se robustece com maior ênfase em razão das referidas entidades serem constituídas por meio de capital misto, inclusive advindo de particulares, mesmo que em minoria. 
Como terceiro ponto essencial do trabalho, consideram-se duas circunstâncias: a) que em razão do tipo de regime jurídico aplicado às referidas entidades, haveria a possibilidade da incidência das normativas e sistemáticas relativas à falência e à recuperação judicial, nos moldes da Lei $\mathrm{n}^{\mathrm{o}} 11.101 / 2005$ e; b) o artigo $2^{\circ}$ da Lei 11.101/2005 seria, em tese, inconstitucional, pois afrontaria diretamente as disposições expostas no artigo $173, \S 1^{\circ}$, II da Constituição Federal.

Importante sopesar, ainda, a observação de que tais situações poderiam se estender para as Empresas Públicas que também atuam no domínio econômico.

De outra forma, não incidiria a referida lógica em face de entidades que exercem a Prestação de Serviços Públicos, em razão da forma como se estabelece a sua relação com os bens correlatos, considerados públicos.

Foram salientadas, ainda, as diferenças doutrinárias pontuais sobre o assunto abordado, havendo determinadas divergências, mesmo que mínimas, quanto a aplicação das regras de falência e recuperação judicial em face das correlatas entidades, especialmente em razão da indicação de mitigação existente quanto ao regime jurídico privado incidente.

Por fim, verifica-se a resposta possível ao questionamento principal, objeto do presente trabalho, valendo-se da lógica de que a sistemática legislativa de recuperação judicial e de falência deve ser aplicada às Sociedades de Economia Mista que exercem atividade econômica, indicando-se que possivelmente há inconstitucionalidade no artigo $2^{\circ}$ da Lei 11.101/2005, mesmo que parcial, já que a referida sistemática não restaria cabível para as Sociedades de Economia Mista que exercem prestação de serviços públicos, em razão do regime jurídico a que seus bens se submetem.

\section{REFERÊNCIAS}

BEZERRA FILHO, Manoel Justino. Lei de recuperação de empresas e falências comentada. São Paulo: RT, 2009.

BÔAS, Regina Vera Villas; MARUCO, Fábia de Oliveira Rodrigues. Recuperação Judicial: Instrumento Jurídico de Concretização da Função Social e Ambiental da Empresa e Mantenedor da Fonte Geradora de Empregos e das Gerações Presentes e Futuras. Revista Jurídica, [S.1.], v. 4, n. 53, p. 357 - 377, dez. 2018. ISSN 2316-753X. Disponível em: $<$ http://revista.unicuritiba.edu.br/index.php/RevJur/article/view/3223/371371739>. Acesso em: 25 abr. 2020. doi:http://dx.doi.org/10.21902/revistajur.2316-753X.v53i4.3223.

BRASIL. Constituição Federal. Brasília, DF, out 1988. 
BRASIL. Decreto-Lei 200/1967, de 25 de fev de 1967. Dispõe sobre a organização da Administração Federal, estabelece diretrizes para a Reforma Administrativa e dá outras providências. Brasília, DF, fev 1967.

BRASIL. Lei ${ }^{\circ}$ Lei 6.404 , de 15 de dez de 1976. Dispõe sobre as Sociedades por Ações. Brasília, DF, dez 1976.

BRASIL. Lei $\mathrm{n}^{\circ}$ Lei 11.101 , de 09 de fev de 2005. Regula a recuperação judicial, a extrajudicial e a falência do empresário e da sociedade empresária. Brasília, DF, fev 2005.

BRASIL. Lei $\mathrm{n}^{\circ}$ Lei 13.140 , de 26 de jun de 2015. Dispõe sobre a mediação entre particulares como meio de solução de controvérsias e sobre a autocomposição de conflitos no âmbito da administração pública; altera a Lei $n^{\circ}$ 9.469, de 10 de julho de 1997, e o Decreto $n^{\circ}$ 70.235, de 6 de março de 1972; e revoga 0 \$ $2^{\circ}$ do $\operatorname{art.~}^{\circ}$ da Lei $n^{\circ} 9.469$, de 10 de julho de 1997. Brasília, DF, jun 2015.

BRASIL. Lei $n^{\circ}$ Lei 13.303, de 30 de jun de 2016. Dispõe sobre o estatuto jurídico da empresa pública, da sociedade de economia mista e de suas subsidiárias, no âmbito da União, dos Estados, do Distrito Federal e dos Municípios. Brasília, DF, jun 2016.

CORRÊA-LIMA, Osmar Brina; CORRÊA-LIMA, Sérgio Mourão. Comentários à nova lei de falência e recuperação de empresas. Rio de Janeiro: Forense, 2009.

DI PIETRO, Maria Sylvia Zanella. Direito Administrativo. 28. ed. São Paulo: Atlas, 2015.

JUSTEN FILHO, Marçal. Curso de Direito Administrativo. São Paulo: Saraiva, 2005.

MAGALHÃES, Giovani. A submissão das sociedades de economia mista e das empresas públicas ao regime jurídico falimentar previsto na lei 11.101/05. Revista Controle Doutrina e Artigos, Ceará, V. 9, p. 335-353, Junho 2011

MEIRELLES, Hely Lopes. Direito Administrativo Brasileiro. 37. ed. São Paulo: Malheiros, 2011.

MELlO, Celso Antônio Bandeira de. Curso de Direito Administrativo. 32. ed. São Paulo: Malheiros, 2015.

MELLO, Celso Antônio Bandeira de. Grandes temas de Direito Administrativo. 1. ed. São Paulo: Malheiros, 2009.

RAMOS, César Augusto Simões; NETO, Alcelyr Valle Da Costa. Da falência à recuperação judicial: distinções nos processos de pequena e grande empresa. Percurso, [S.1.], v. 3, n. 30, p. 235 - 236, dez. 2019. ISSN 2316-7521. Disponível em: $<$ http://revista.unicuritiba.edu.br/index.php/percurso/article/view/3672/371372044>. Acesso em: 25 abr. 2020.

SCHIAVON, Eliza; BELNOSKI, Alexsandra Marilac. Os créditos com garantias especiais no regime de recuperação empresarial. Percurso, [S.1.], v. 1, n. 12, p. 330-350, jan. 2013. ISSN 2316-7521. Disponível em: <http://revista.unicuritiba.edu.br/index.php/percurso/article/view/539/421 >. Acesso em: 25 abr. 2020. 
SILVA, José Afonso da. Curso de direito constitucional positivo. 41. ed., rev. e atual. até emenda constitucional n. 99 de 14.12.2017. São Paulo: Malheiros, 2018.

STF. Ação Direita de Inconstitucionalidade: ADI 1.642. Rel. Min. Eros Grau, j. 3-4-2008, DJE de 19-9-2008, 2008.

TOMAZETTE, Marlon. Curso de direito empresarial. V. 3. 3. ed. São Paulo: Atlas, 2014.

WINTER, Neusa Maria Carta; OLIVEIRA, Francisco Cardozo. O papel da recuperação judicial em face das crises da empresa e o pressuposto de sustentabilidade da atividade empresarial. Revista Jurídica, [S.1.], v. 4, n. 33, p. 380-406, dez. 2013. ISSN 2316-753X. Disponível em: <http://revista.unicuritiba.edu.br/index.php/RevJur/article/view/764/589>. Acesso em: 25 abr. 2020. doi:http://dx.doi.org/10.21902/revistajur.2316-753X.v4i33.764.

ZAGO, Felipe do Canto. (In) Constitucionalidade do artigo $2^{\circ}$, I, da Lei 11.101/05 numa interpretação sistemática com o artigo 173, § 1º da Constituição Federal. 2010. Dissertação (Mestrado em Direito), Pontifícia Universidade Católica do Rio Grande do Sul, Rio Grande do Sul. 